\title{
AIDS-Related Plasmablastic Lymphoma of the Oral Mucosa
}

National Cancer Institute

\section{Source}

National Cancer Institute. AIDS-Related Plasmablastic Lymphoma of the Oral Mucosa. NCI Thesaurus. Code C9016.

A plasmablastic oral mucosa lymphoma in a patient with acquired immunodeficiency syndrome. 